\title{
Pengunci Pintu Via Wifi Berbasis Mikrokontroler Arduino Uno R3
}

\author{
Ernes Cahyo Nugroho*1, Paryanta ${ }^{2}$, Syahrial Fikri ${ }^{3}$ \\ ${ }^{1}$ Program Studi Sistem Komputer, STMIK AUB, Surakarta, Indonesia \\ ${ }^{2,3}$ Program Studi Teknik Komputer, STMIK AUB, Surakarta, Indonesia \\ e-mail:*1ernes.cahyo@stmik-aub.ac.id,2paryanta@stmik-aub.ac.id
}

\begin{abstract}
Abstrak
Kemajuan teknologi yang sangat pesat memungkinkan adanya berbagai usaha untuk memberikan kemudahan dan kenyamanan bagi manusia. Alat kontrol merupakan sebuah inovasi yang hadir karena ketertarikan manusia untuk menciptakan sebuah alat yang dapat mengendalikannya secara cepat dan aman. Salah satunya adalah alat pengunci rumah yang saat ini masih banyak yang manual Pemilik rumah harus mendekat untuk mengunci pintu. Kunci rumah sangat kecil serta mudah hilang dan ditambah lagi kita harus menduplikasi kunci agar dapat di gunakan setiap orang. Penelitian ini menggunakan metode Research and Development yaitu metode yang bertujuan menghasilkan atau mengembangkan produk tertentu.

Dalam hal ini dibuatlah sebuah alat sistem pengunci pintu yang di kontrol dengan menggunakan komputer atau smartphone. Komputer atau smartphone sebagai media pengendali, modul Wifi sebagai media penghubung dan Arduino Uno sebagai pusat pengendali dan pengolahan data yang nantinya akan memberikan perintah kepada mo tor servo sebagai penggerak untuk mengunci pintu. Tujuan dari penelitian ini adalah untuk mempermudah penghuni rumah untuk mengunci pintu.

Berdasarkan pengujian yang telah dilakukan baik pada mekanik maupun pada elektronika yang telah dibuat serta melihat tujuan dari penelitian, mak a dapat disimpulkan bahwa alat telah diuji dan dapat digunakan untuk membantu penghuni rumah.
\end{abstract}

Kata kunci-Arduino Uno, Android, Wifi, Smartphone, Keamanan Rumah, Motor Servo

\section{Abstract}

The rapid technological advancement allows for various efforts to provide convenience and comfort for humans. The controller is an innovation that is present because of human interest to create a tool that can control it quickly and safely. One of them is a house locking tool that is still a lot of manual. House owners must approach to lock the door. The key to the house is very small and easy to lose and plus we have to duplicate the keyfor everyone to use. This research uses Research and Development method is a method that aims to produce or develop a particular product.

In this case a locking system door device is controlled using a computer or smartphone. Computers or smartphones as a controlling medium, Wifi module as media liaison and Arduino Uno as the center of control and data processing which will give command to servo motor as drive to lock the door. The purpose of this study is to facilitate the inhabitants of the house to lock the door.

Based on the tests that have been done both on the mechanics and on the electronics that have been made and see the purpose of the research, it can be concluded that the tool has been tested and can be used to help residents.

Keywords-Arduino Uno, Android, Wifi, Smartphone, Keamanan Rumah, Motor Servo 


\section{PENDAHULUAN}

Pada jaman yang semakin maju dan modern ini, teknologi berkembang begitu pesat guna memenuhi kebutuhan hidup manusia. Dengan adanya perkembangan teknologi tentu saja ilmu Komputer juga berkembang. Dalam hal ini ilmu komputer sangat berpengaruh terhadap kehidupan manusia. Hal ini mendorong manusia untuk membuat hardware dan software yang mendukung perkembangan teknologi dan ilmu computer dunia untuk memudahkan user dalam berkomunikasi dengan komputer.

Arduino merupakan pengendali mikro single-board yang bersifat open-source, diturunkan dari Wiring platform, dirancang untuk memudahkan penggunaan elektronik dalam berbagai bidang. Hardwarenya memiliki prosesor Atmel AVR dan softwarenya memiliki bahasa pemrograman sendiri.

Arduino Uno adalah salah satu jenis Arduino yang memiliki memiliki 14 digital pin input / output (dimana 6 dapat digunakan sebagai output PWM), 6 input analog, resonator keramik 16 $\mathrm{MHz}$, koneksi USB, jack listrik, header ICSP dan tombol reset. Ini berisi semua yang diperlukanuntuk mendukung mikrokontroler; hanya menghubungkannya ke komputer dengan kabel USB atau power itu dengan adaptor AC-DC atau baterai untuk memulai menggunakannya.

Lalu salah satu teknlogi yang umum di gunakan saat ini adalah wifi. Wifi adalah sebuah teknologi yang memanfaatkan peralatan elektronik untuk bertukar data secara nirkabel (menggunakan gelombang radio) melalui sebuah perangkat. Dengan wifi kita dapat mengendalikan suatu alat. Contohnya pengunci pintu. Kunci memegang peran penting dalam sebuah sistem keamanan. Kunci pintu rumah yang ada sekarang ini sebagian besar masih menggunakan kunci mekanik konvensional yang mudah di duplikasikan, yang bias membuat rumah kita rawan dengan pencurian. Perkembangan teknologi digital memberikan solusi dalam sebuah sistem kunci sebagai pengaman yang lebih baik

Dalam hal ini dibuatlah sebuah alat pengunci pintu yang di kontrol dengan menggunakan laptop atau smartphone. Dengan adanya sistem kontrol ini penulis berharap akan mempermudah pemilik yang tidak bersusah payah membuka tutup kunci. Alat kunci ini memanfaatkan teknologi Wifi pada Laptop dan smartphone yang dihubungkan ke modul Wifi pada Arduino, sebagai input untuk membuka dan mengunci pintu. Alat ini merupakan serangkaian komponen yang dapat mengunci dan membuka kunci pintu rumah yang dikontrol menggunakan program IDE Arduino.

Maka dari itu dalam kesempatan ini penulis mencoba mempersembahkan sebuah karya penelitian dengan judul "Pengunci Pintu Via Wifi Berbasis Mikrokontroler Arduino Uno R3".

\section{METODE PENELITIAN}

Dalam bagian ini akan diuraikan bagaimana analisis sistem yang digunakan, perancangan akses pengunci pintu menggunakan wifi dengan aplikasi pengontrol berbasis web dan Arduino sebagai kontrol dengan menggunakan perangkat lunak Arduino IDE. Dalam perancangan ada beberapa tahapan yang harus dilakukan diantaranya dimulai dengan pembuatan blok diagram perancangan sistem yang digunakan.

\subsection{Blok Diagram}

Diagram blok merupakan gambaran umum mengenai prinsip kerja yang akan dibuat. Secara umum cara kerja alat pengunci pintu dapat dilihat pada diagram blok yang ditunjukkan pada gambar 1 . 


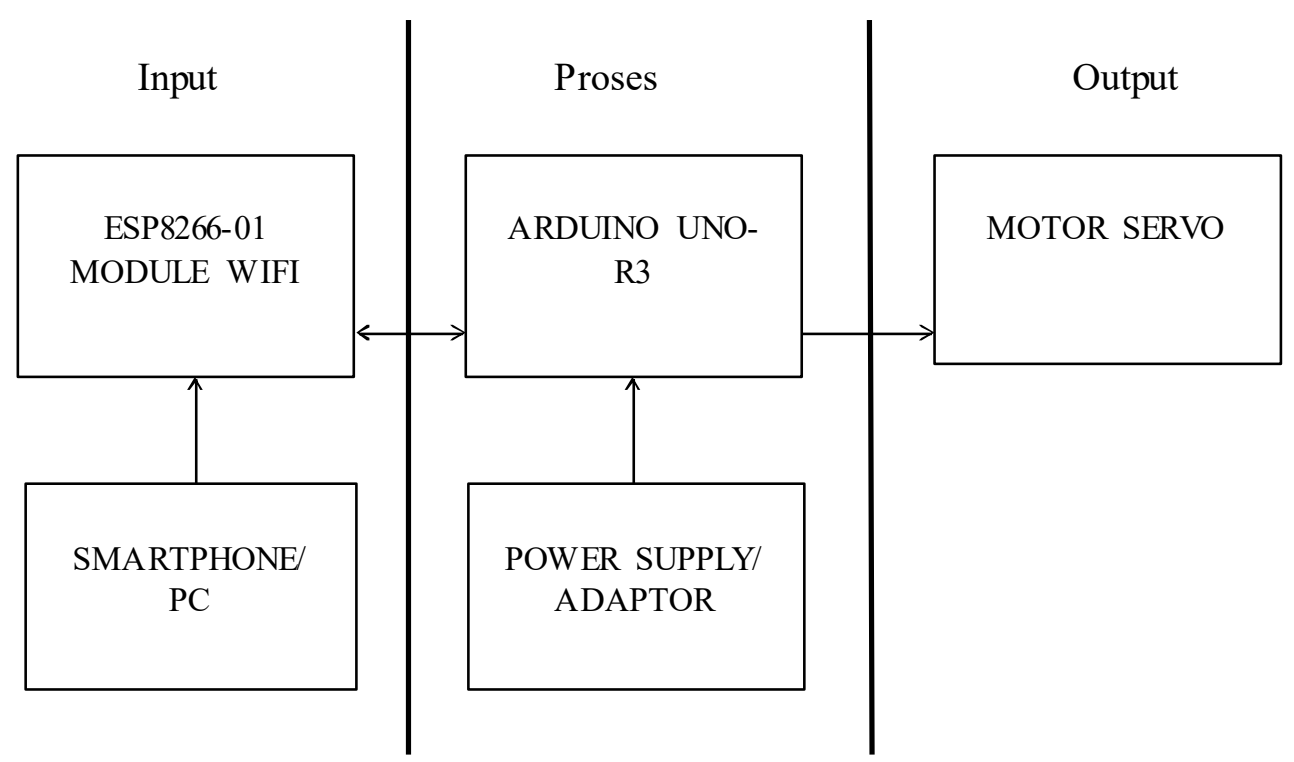

Gambar 1 Diagram Blok Rangkaian Pengunci pintu

\subsection{Diagram Alir}

Diagram alir (flowchart) adalah gambaran secara grafik yang terdiri dari simbol-simbol dari algoritma-algoritma dalam suatu program yang menyatakan arah alur suatu program, diagram alur merupakan dasar dari pemograman.

Diagram alur perlu dibuat sesuai dengan perangkat keras yang dibuat, agar program yang dibuat terstruktur dan jelas. Selain itu juga alur program yang akan dibuat jelas. Diagram alur pembuatan pengunci pintu dapat dilihat pada gambar 2 .

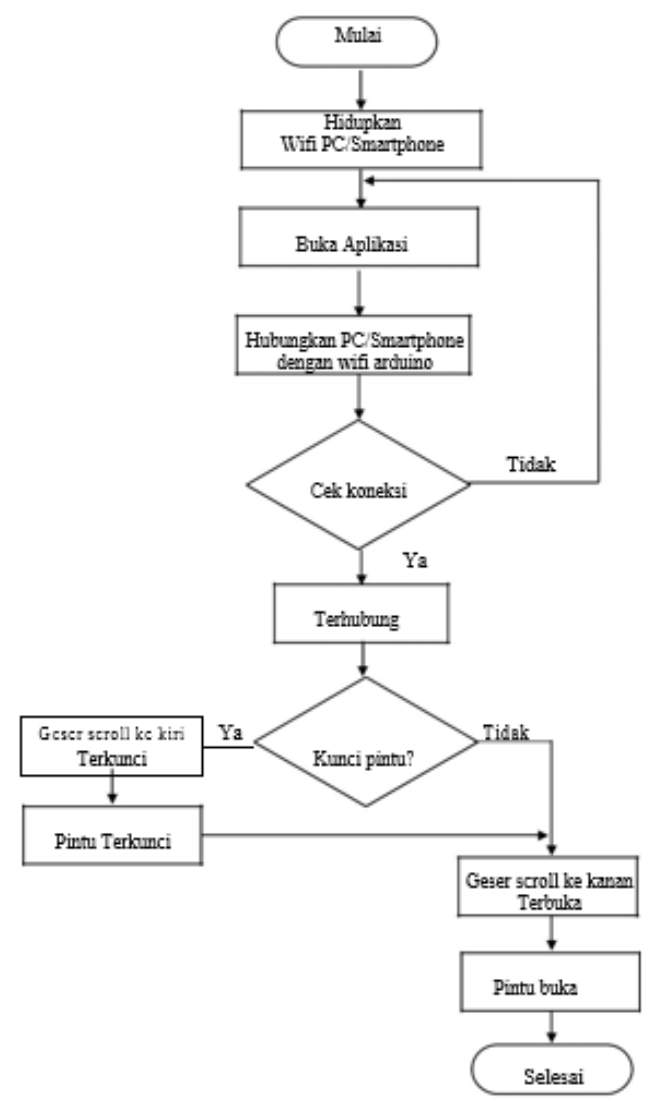

Gambar 2. Alur flowchart 
Dari Gambar 2 dapat dilihat bahwa program yang dibuat adalah sistem untuk pengguna. Pertama hubungkan wifi smartphone/pc dengan wifi arduino aplikasi dibrowser Pengguna bisa menggeser scroll ke kanan untuk membuka mengunci pintu atau menggeser scroll ke kiri untuk menutup pintu.

\subsection{Perancangan Mekanik}

Perancangan mekanik dibuat untuk membantu dalam membuat sebuah alat. Perancangan mekanik juga dapat mendukung kinerja alat. Dalam pembuatan alat pengunci pintu ditempatkan di sebuah papan untuk meletakkan komponen-komponen. Perancangan mekanik dapat dilihat pada Gambar 3 berikut.

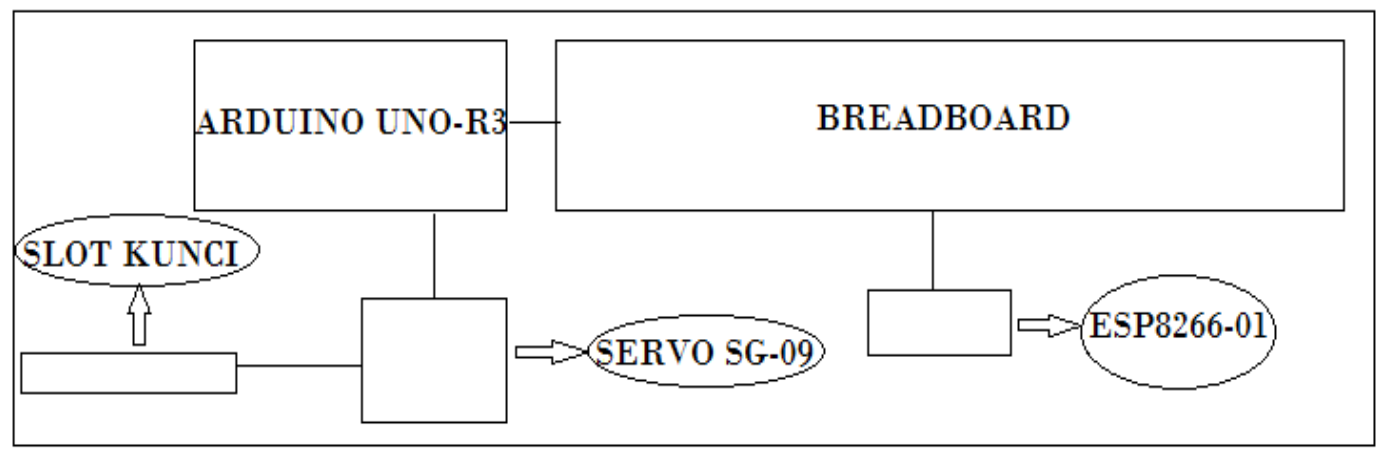

Gambar 3 Perancangan Mekanik

\subsection{Rangkaian Keseluruhan}

Perancangan perangkat keras meliputi keseluruhan yang berhubungan dengan rancangan dan pembuatan alat secara fisik, berikut Gambar 4 perancangan perangkat keras yang dibuat.

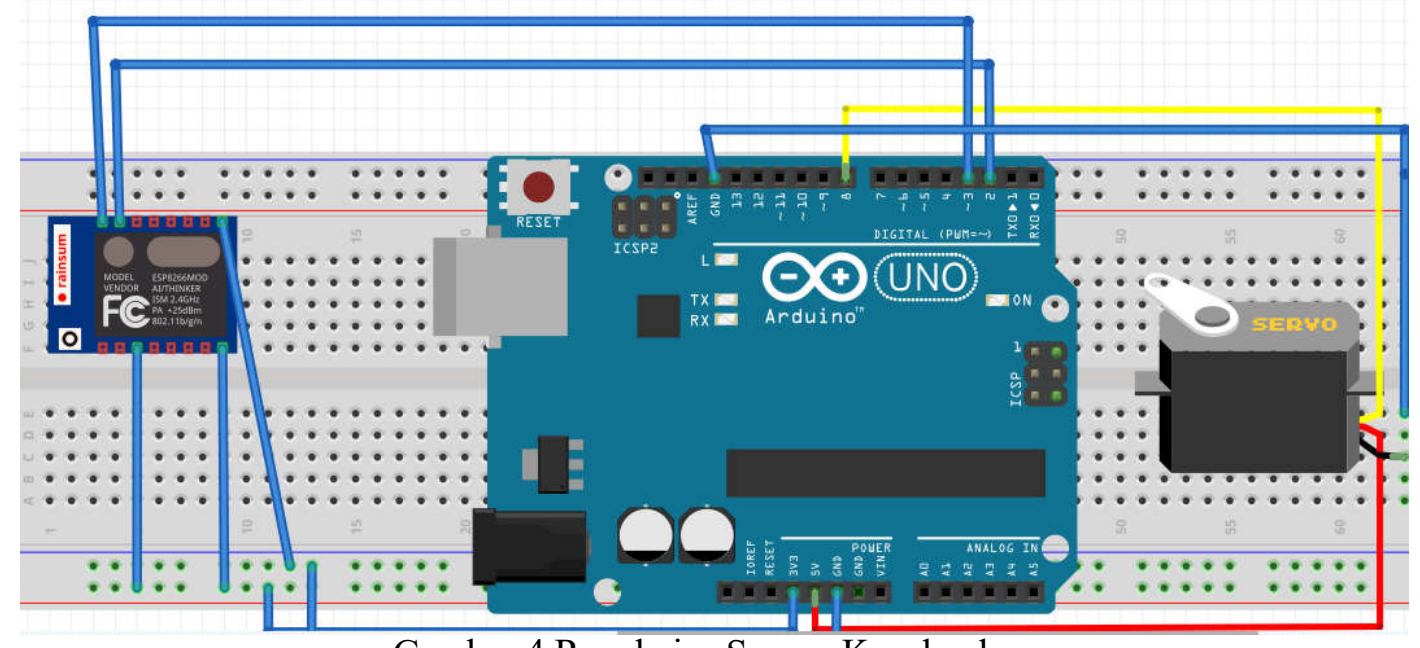

Gambar 4 Rangkaian Secara Keseluruhan

Gambar 4 menunjukkan gambar rangkaian secara keseluruhan dimana rangkaian terdapat Arduino, Wifi dan motor servo yang sudah terhubung dengan masing-masing pin.

\subsection{Pembuatan Web}

Dalam pembuatan sistem ini, digunakan Komputer atau smartphone untuk mengkontrol pengunci. Pertama akan merancang tampilan awal aplikasi yang mengkontrol alat. Untuk lebih jelasnya dapat dilihat Gambar 5 rancangan tampilan dibawah ini.

1. Halaman Login 
2. Halaman Pengendali

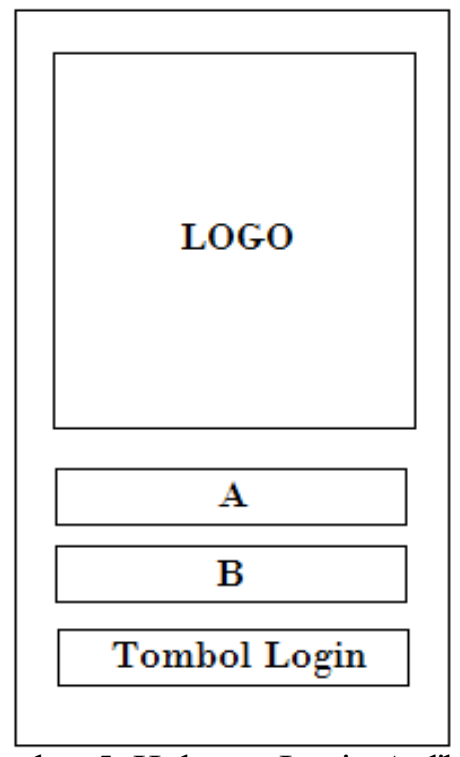

Gambar 5. Halaman Login Aplikasi

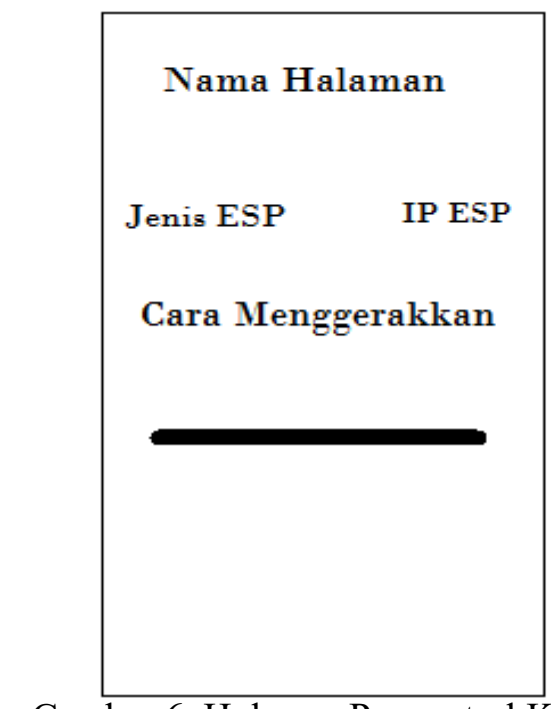

Gambar 6. Halaman Pengontrol Kunci

\section{HASIL DAN PEMBAHASAN}

\subsection{Pengujian Board Arduino}

Pengujian Board Arduino menggunakan I/O digital pada pin D0 - D13. Pengujian dilakukan dengan memasukkan program sederhana (Scan Wifi) dan mengukur tegangan pada masing-masing pin I/O dengan periode $100 \mathrm{~ms}$ low dan $100 \mathrm{~ms}$ high secara bergantian. Tabel 1 dibawah ini menunjukkan hasil pengujian pada rangkaian Arduino.

Tabel 1. Hasil pengujian Board Arduino

\begin{tabular}{|c|c|c|c|}
\hline No & Pin digital I/O & Tegangan Low & Tegangan High \\
\hline 1 & D0 & 0 & $5.1 \mathrm{~V}$ \\
2 & D1 & 0 & $5.1 \mathrm{~V}$ \\
3 & D2 & 0 & $5.1 \mathrm{~V}$ \\
4 & D3 & 0 & $5.0 \mathrm{~V}$ \\
5 & D4 & 0 & $5.1 \mathrm{~V}$
\end{tabular}




\begin{tabular}{|c|c|c|c|}
6 & D5 & 0 & $5.0 \mathrm{~V}$ \\
7 & D6 & 0 & $5.0 \mathrm{~V}$ \\
8 & D7 & 0 & $5.1 \mathrm{~V}$ \\
9 & D8 & 0 & $5.1 \mathrm{~V}$ \\
10 & D9 & 0 & $5.0 \mathrm{~V}$ \\
11 & D10 & 0 & $5.0 \mathrm{~V}$ \\
\hline 12 & D11 & 0 & $4.9 \mathrm{~V}$ \\
13 & D12 & 0 & $5.1 \mathrm{~V}$ \\
14 & D13 & 0 & $5.1 \mathrm{~V}$
\end{tabular}

\subsection{Pengujian Alat Keseluruhan}

Pada tahap ini akan dilakukan pengujian alat secara keseluruhan yaitu dengan menguji sebuah alat pengunci pintu via wifi berbasis mikrokontroler Arduino Uno R3 yang telah dirancang apakah dapat berjalan dengan baik atau tidak seperti Gambar 7 berikut.

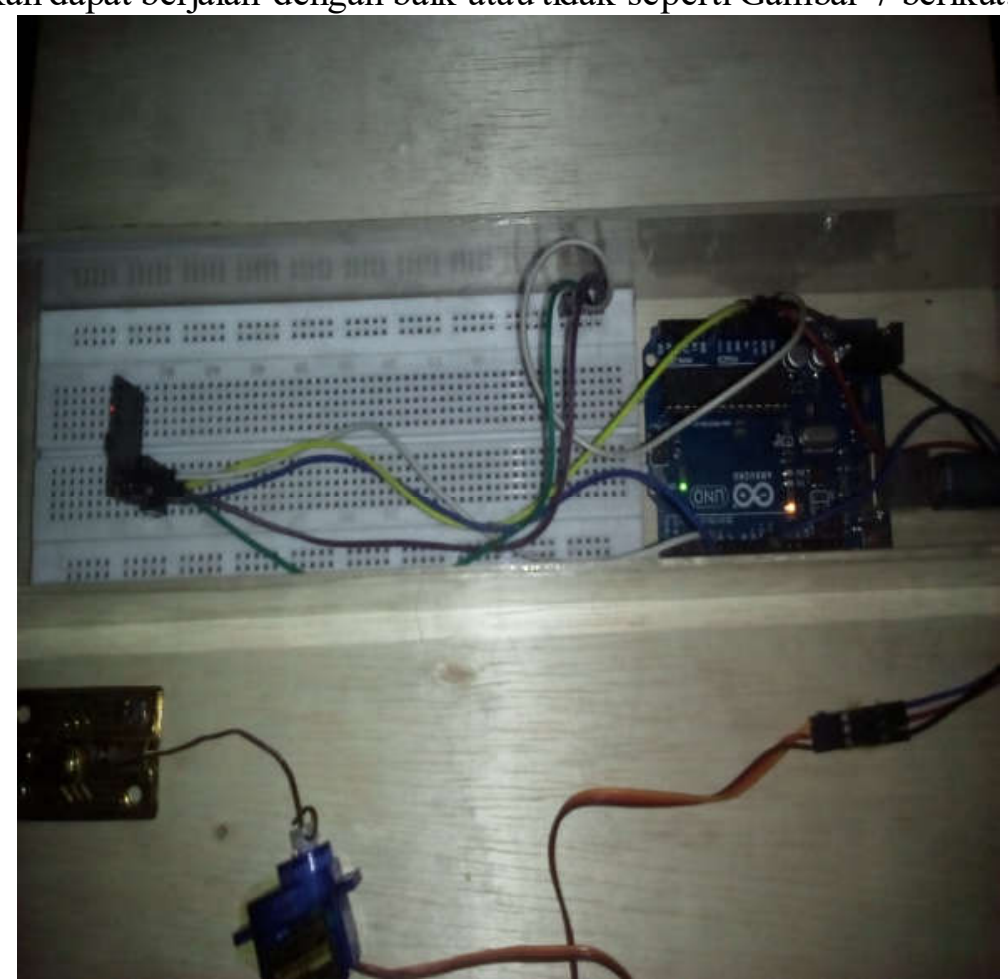

Gambar 7. Alat Keseluruhan

Langkah prosedur pengujian alat adalah sebagai berikut:

1. Hubungkan Adaptor 5V DC pada input Arduino.

2. LED pada ESP8266-01 Wifi Molule dan Arduino akan menyala apabila power sudah dihubungkan.

3. Hidupkan Wifi Smartphone atau $P C$ dan pasangkan Wifi arduino dengan Wifi smartphone atau $P C$.

4. Cek Status Wifi apakah sudah terhubung atau belum di Smartphone atau $P C$.

5. Buka aplikasi web lalu login.

6. Scroll ke kanan untuk membuka scroll ke kiri untuk mengunci.

\subsection{Pembahasan}

Alat pengunci pintu ini bisa di kendalikan dengan aplikasi yang di akses melalui browser smartphone atau komputer. 
Arduino akan menerima perintah yang dikirim oleh smartphone atau laptop yang telah terhubung dengan wifi arduino melalui Aplikasi. Output dari perintah tersebut adalah bergeraknya servo yang akan mendorong atau menarik kunci.

Cara penggunaan alat sebagai berikut:

1. Sambungkan wifi Smartphone atau komputer dengan wifi arduino. Wifi arduino disini memaikai SSID : esp_123 dan Password: 1234567890

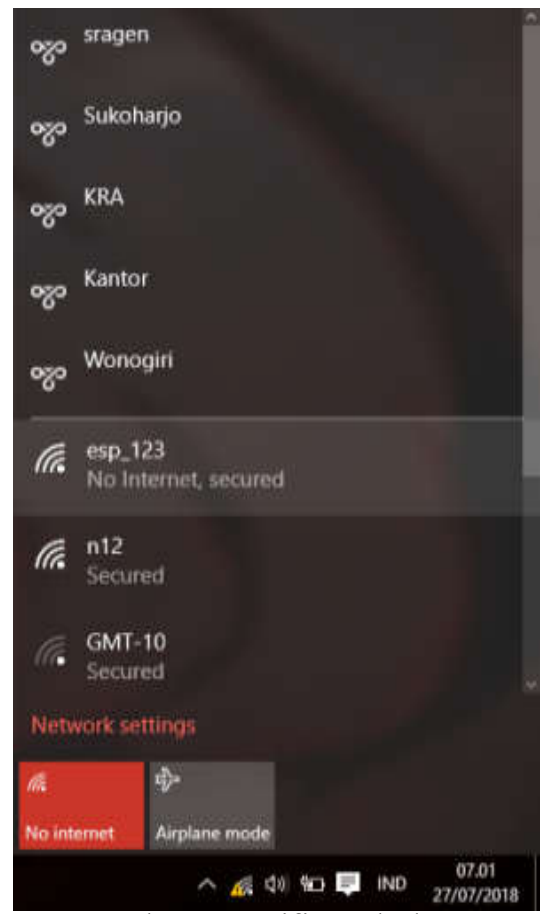

Gambar 8. Wifi Terhubung

2. Buka aplikasi dengan browser lalu lakukan login dengan Username: admin dan Password: admin

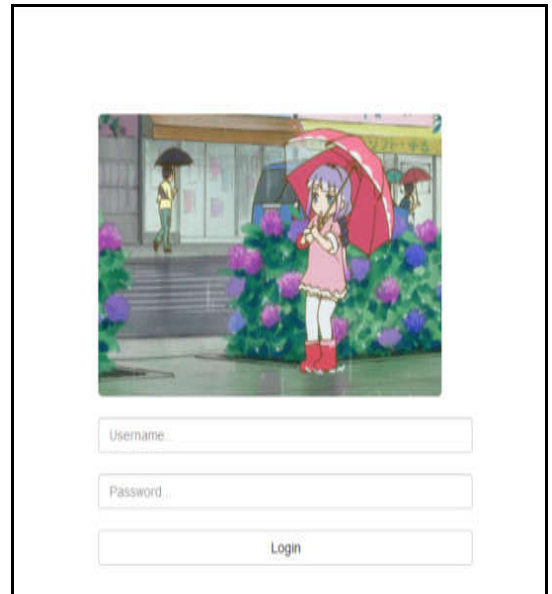

Gambar 9. Halaman Login

3. Halaman ini digunakan untuk pengontrolan alat 


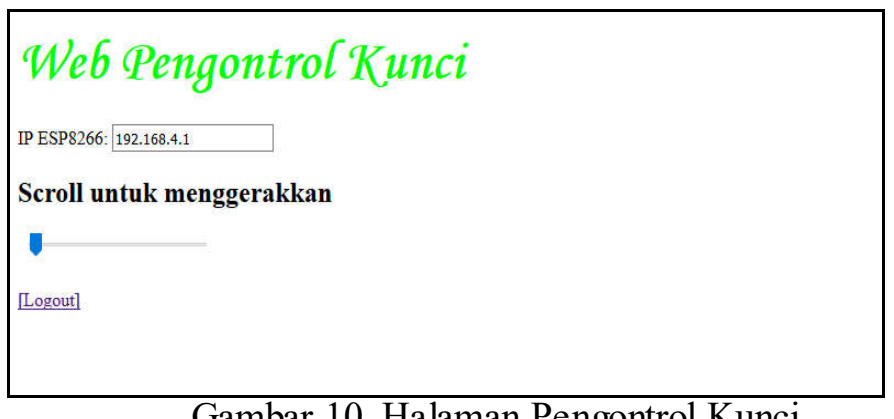

4. Scroll ke kiri untuk mengunci.

5. Scroll ke kanan untuk membuka.

\section{KESIMPULAN}

Pada penelitian ini dilakukan pembuatan Alat Pengunci Via Wifi Berbasis Arduino Uno R3. Dari hasil pembuatan Tugas Akhir ini dapat disimpulkan sebagai berikut:

1. Penggunan alat ini digunakan untuk mengunci yang memanfaatkan smartphone atau komputer sebagai pengendalinya dan ESP8266-01 Wifi Module sebagai penghubung ke mikrokontroler Arduino Uno R3. Pengunci dapat dikendalikan dengan browser yang terdapat pada smartphone atau komputer pengguna.

2. Rangkaian alat dan aplikasi ini baik dan sesuai yang di harapkan.

\section{SARAN}

Saran yang dapat penulis berikan untuk pengembangan sistem ini selanjutnya antara lain:

1. Menambah pengunci tertentu agar lebih aman dan mencegah penghuni luar masuk kerumah.

2. Menambah 1 buah motor servo untuk menggerakkan L slot kunci agar kunci lebih kencang.

3. Menambah sebuah pesan/informasi yang ditujukan kepada pengguna aplikasi untuk mengetahui status terakhir pengunci dan siapa yang menggunakan kunci.

\section{DAFTAR PUSTAKA}

[1] Alexander F. K. Sibero, 2011, Kitab Suci Web Programming, MediaKom, Yogyakarta.

[2] Apriyani, Eka.2016. Kunci Pintu Otomatis Via Bluetooth

[3] Arduino. (2017, April) ARDUINO UNO. [Online]. http://arduino.cc

[4] Bunafit Nugroho. 2008. Aplikasi Pemrograman Web Dinamis Dengan PHP dan MySQL. Gava Media, Yogyakarta.

[5] Kurniawan, Yayak Agung.2016: Alat Pengunci P intu Otomatis berbasis Mikrokontroler

[6] Prastya, Nurul Huda K.A .2016: Kunci pintu rumah berbasis mikrokontroler Arduino Uno dan RFID (Radio Frequency Identification)

[7] Sulaiman, Arif. 2012. ARDUINO: Mikrocontroller bagi Pemula hingga Mahir. https://widuri.raharja.info/index.php/SI1 133469938 (Diakses Pada 5 Mei 2018)

[8] Sulaiman, Arif 2012. ARDUINO: Mikroontroller bagi Pemula hingga Mahir

[9] Simarmata, Janner. 2006. Pengamanan Sistem Komputer. Penerbit CV. ANDI OFFSET, Yogyakarta.

[10] Suryana, Taryana dan Koesheryatin.2014. Aplikasi Internet Menggunakan HTML, CSS, JavaScript. Jakarta: PT Alex Komputindo. 
[11] Saputra, Agus dan Feni Agustin. 2011. Pemrograman CSS untuk pemula, Jakarta: PT Elex Media Komputindo

[12] Widodo, Budiharto. 2008. "Panduan Praktikum Mikrokontroler AVR ATmega16". Jakarta. Elex Media Komputindo.

[13] Wicaksono, M. Fajar.2017. Mudah Belajar Komputer Arduino.Informatika

[14] Winarno, Edy, dkk. 2014. Pemrograman Web Berbasis HTML5, PHP, dan JavaScript. Jakarta:Elex Media Komputindo. 